\title{
Numerical Analysis of Shear Behavior of High-Strength Reinforced Concrete Columns
}

\author{
Teddy Yustiono ${ }^{1}$, Harun Alrasyid ${ }^{1}$, Pujo Aji ${ }^{1}$, Yu Chen-Ou ${ }^{2}$, Yusronia Putri ${ }^{1}$ \\ Civil Engineering Department, Institut Teknologi Sepuluh Nopember, Surabaya, Indonesia ${ }^{1}$ \\ Civil Engineering Department, National Taiwan University, Taipei, Taiwan ${ }^{2}$
}

\begin{abstract}
Although the utilization of high-strength concrete and high-strength steel can reduced column dimension at high-rise building, the column aspect ratio remain low. These column were tended to dominate by shear failure than flexure failure. The research discusses the numerical analysis of shear critical of Highstrength reinforced concrete columns. The Uniaxial Shear Flexure Method (USFM) was used to observe this behavior and examined on the test result. This study showed that USFM method provided conservative prediction. Some modification was proposed in order to improve this method when estimate the shear behaviour of high-strength reinforced concrete column.
\end{abstract}

Keywords—high strength reinforced concrete columns, numerical analysis, shear behaviour.

\section{INTRODUCTION}

$\mathrm{V}$ ertical residential development is increasingly being built in many large cities, especially in metropolitan cities. Many developers are competing to create a high vertical residential building, and that cause making challenge for Civil Engineering. There are many alternatives to build a building, but the reinforced concrete system is the most profitable method, because it is resistant to fire [1], a good durability, cheap, rigid and also low maintenance cost. The advantage using the concrete is the size of the structure element, especially column concrete. Therefore high-strength reinforced concrete is an option to reduce its size.

The study about high strength reinforced concrete has been developed in Japan in 1990-1995. In 1998, Japan stated to help research project titled "Development of the Advanced Reinforced Concrete Buildings using highstrength concrete and high-strength reinforcement [2]. The research project started by concrete compressive strength between $40 \mathrm{MPa}$ until $100 \mathrm{MPa}$ and used reinforcement yield strength between $400 \mathrm{MPa}$ until $1200 \mathrm{MPa}$. After several years, Japan produces highstrength concrete with compressive strength between 40 $\mathrm{MPa}$ until $100 \mathrm{MPa}$ and also produces longitudinal reinforcement with yield strength between $650 \mathrm{MPa}$ until $980 \mathrm{MPa}$ and produces transversal reinforcement with yield strength between $785 \mathrm{MPa}$ until $1275 \mathrm{MPa}$. [3]

When the earthquake is occurred, the shear failure of column must be avoided. The shear failure of column is caused by lost of strength rapidly. Harun Alrasyid [3] have done the experimental about shear failure of column. In general, the result from experimental stated three things; (1) if the axial load that applied in experimental is more large, then the shear strength concrete is larger too, (2) transversal reinforcement yield strength doesn't satisfied, (3) if the axial load that applied in experimental is more large, then the lost of shear strength in column is faster.

Nowadays, the study of numerical analysis about shear behavior of high strength reinforced concrete column is still little bit. In general, the behavior of element structure has analyzed with finite element method. However, the usage of finite element method in element structure took high cost and long time to analyzed it. Therefore, alternative method is needed to predict about behavior of shear strength in concrete column.

ASFI (Axial Shear Flexure Method) is one of the alternative method to predict behavior of shear strength in concrete column. This method used combination between section analyzes and Modified Compression Field Theory (MCFT) to predicted about behavior of shear and bend from strength reinforced concrete columns. Because MCFT has complicated iteration to predict the behavior shear strength of concrete column, therefore H.Mostafaei and F.J.Vecchio [4] proposed the Uniaxial Shear Flexure Method (USFM). This method simplifies and eliminates process iteration in shear model from ASFI. Both methods have good precision to predict the shear behavior of high strength reinforced concrete columns.

\section{METHOD}

The ASFI method is comprised of two models: a flexure model based on traditional uniaxial section analysis, and a shear model based on a biaxial shear element approach. The total lateral drift of the column between two sections $\gamma$ is taken as the sum of shear strain $\left(\gamma_{s}\right)$ and the flexural drift ratio $\left(\gamma_{f}\right)$ between the two sec- tions. Furthermore, the total axial strain of the column between the two sections $\left(\varepsilon_{x}\right)$ is taken as the sum of axial strains due to axial $\left(\varepsilon_{x a}\right)$, shear $\left(\varepsilon_{x s}\right)$ and flexural $\left(\varepsilon_{x f}\right)$ mechanisms.[4]

$$
\begin{aligned}
& \gamma=\gamma_{s}+\gamma_{f} \\
& \varepsilon_{x}=\varepsilon_{x s}+\varepsilon_{x f}+\varepsilon_{x a}
\end{aligned}
$$




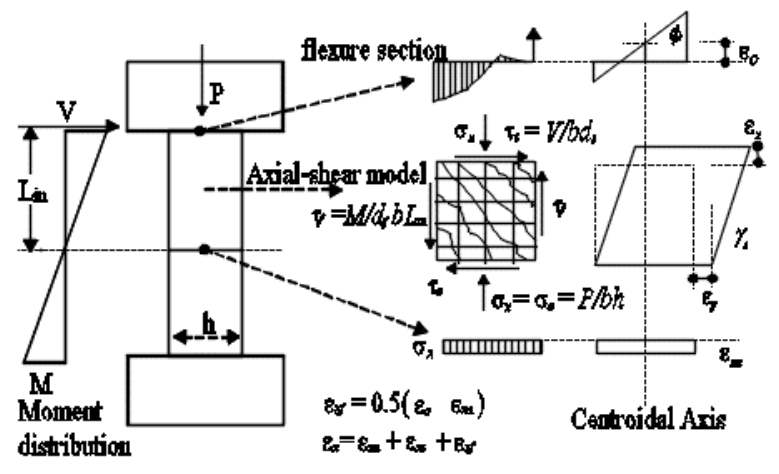

Figure 1. Axial-shear-flexure interaction in ASFI method

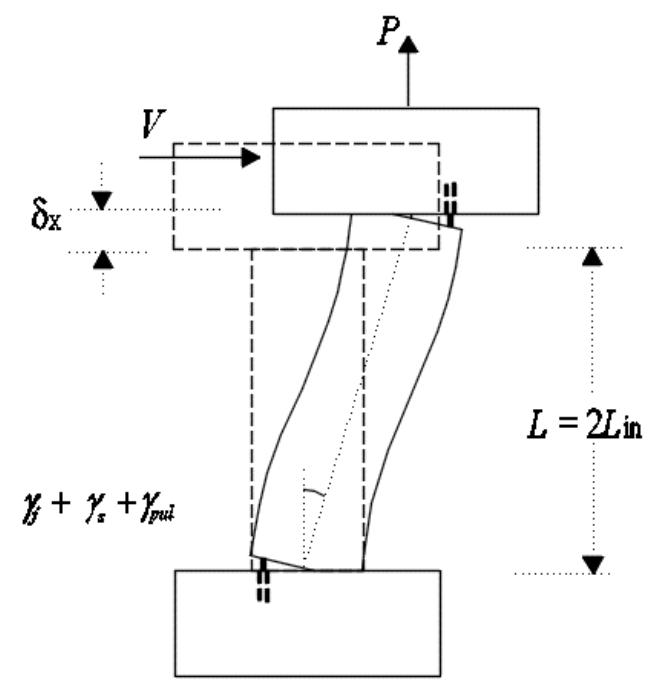

$\delta_{x}=\delta_{x f}+\delta_{x x}+\delta_{x a}+\delta_{x p u l}$

Figure 2. Axial and shear deformations of a column considered by ASFI Method

In Figure 1. There are two end sections for a reinforced concrete column. The total axial deformations are the sum of axial strains developed by axial, shear and flexure.

In Figure 2. Total drift ratio is a combination of shear, flexure and pullout deformation.

The secant stiffness method might be applied for the concrete and reinforcement element in the USFM method as well. Constitutive laws and secant modulus, consider by the USFM approach, for both axial-flexure and axial-shear models, are depicted in Figure 3,4,5. In Figure 3, there are two parameters in confinement, they are parameters $K$ and $Z_{m}$. They can be determined as the modified Kent and Park models for stress-strain relation of concrete confined by rectangular steel hoops. There are also $\beta$ in Figure 3. $\beta$ is compression softening factor. The compression softening factors applied to the concrete compression stress to represent degradation in the concrete strength due to shear deformation. [4]

$K=1+\frac{\rho_{w w} f_{y y}}{f_{c}^{\prime}}, Z_{m}=\frac{0.5}{\frac{3+0.29 f_{c}^{\prime}}{145 f_{c}^{\prime}-1000}+\frac{3}{4} \rho_{w y} \sqrt{\frac{h^{\prime \prime}}{s_{h}}}-K \varepsilon^{\prime}{ }_{c}}$

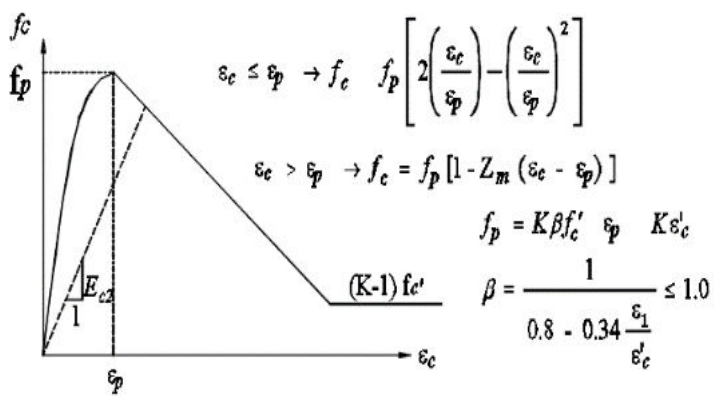

Figure 3. Concrete compression constitutive law

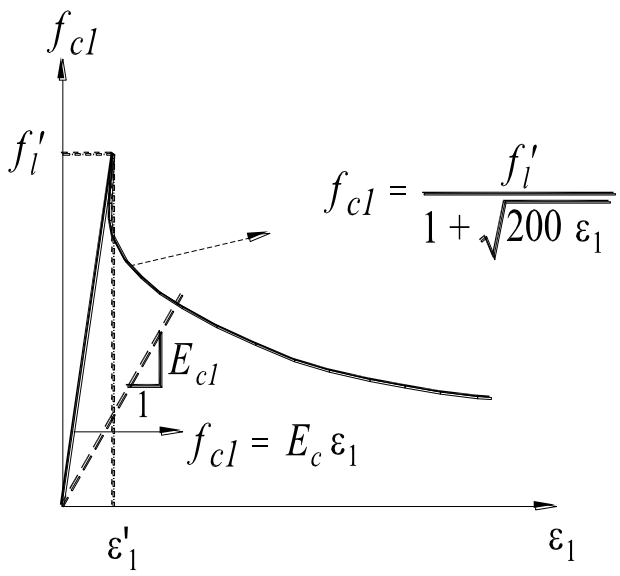

Figure 4. Concrete tensile constitutive law

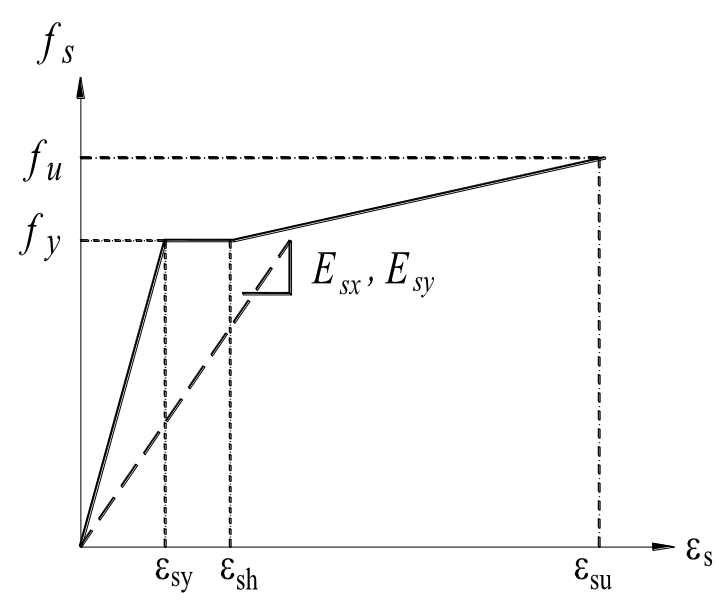

Figure 5. Constitutive law for reinforcing bars

where $\left(\rho_{w w}\right)$ equal the ratio of volume of rectangular steel hoops to volume concrete core measured to outside of the peripheral hoop, $f_{y y}$ equal the yield strength of steel hoop (MPa), $f^{\prime}{ }_{c}$ equals the concrete compression cylinder strength (MPa), $h$ "' equal the width of concrete core measured to outside of the peripheral hoop, $s_{h}$ equal the center-to-center spacing of hoops sets, and $\varepsilon_{c}^{\prime}$ equals the maximum concrete compressive strain. [5] 
Table 1. Columns Dimension

\begin{tabular}{|c|c|c|c|c|c|c|c|c|}
\hline \multirow{2}{*}{ Column } & \multirow{2}{*}{$\begin{array}{l}\text { Axial } \\
\text { Load } \\
\text { Ratio }\end{array}$} & \multirow[t]{2}{*}{$\begin{array}{c}f_{c s}^{\prime} \\
(\mathrm{MPa})\end{array}$} & \multicolumn{2}{|c|}{$\begin{array}{l}\text { Logitudinal } \\
\text { Reinforcement } \\
\text { SD } 685\end{array}$} & \multicolumn{2}{|c|}{$\begin{array}{c}\text { Transversal } \\
\text { Reinforcement } \\
\text { SD } 785\end{array}$} & \multirow[t]{2}{*}{$\begin{array}{c}\text { Dimension } \\
(\mathrm{mm})\end{array}$} & \multirow{2}{*}{$\begin{array}{c}\text { Axial } \\
\text { Compression } \\
\text { Load } \\
(\mathrm{kN})\end{array}$} \\
\hline & & & $\begin{array}{c}f_{y l s} \\
(\mathrm{MPa})\end{array}$ & $I_{l}$ & $\begin{array}{c}f_{y t s} \\
(\mathrm{MPa})\end{array}$ & $l_{t}$ & & \\
\hline A-3.1 & \multirow{2}{*}{0.1} & 92.2 & \multirow{9}{*}{735} & & \multirow{9}{*}{862} & 0.26 & D-13-260 & 3319 \\
\hline A- 6 & & 90.8 & & & & 0.59 & D-13-150 & 3268 \\
\hline B-3.1 & & 79 & & & & 0.26 & D-13-260 & 5616 \\
\hline B-5 & 0.2 & 78 & & & & 0.41 & D-13-160 & 5616 \\
\hline B-6 & & 101.1 & & 3.38 & & 0.59 & D-13-150 & 7272 \\
\hline C-5 & \multirow{2}{*}{0.3} & 79.6 & & (24D25) & & 0.41 & D-13-160 & 8596 \\
\hline$C-6$ & & 80.3 & & & & 0.59 & D-13-150 & 8672 \\
\hline D-5 & \multirow{2}{*}{0.4} & 82.8 & & & & 0.41 & D-13-160 & 11923 \\
\hline D-6 & & 84.9 & & & & 0.59 & D-13-150 & 12225 \\
\hline
\end{tabular}

$\beta=\frac{1}{0.8-0.34 \frac{\varepsilon_{1}}{\varepsilon^{\prime}{ }_{c}}} \leq 1.0$

where $\varepsilon_{c}^{\prime}=$ concrete strain at the cylinder peak uniaxial compressive stress. The average concrete tensile strain $\varepsilon_{1}$ is determined according to two basic assumptions and the fundamental equation of the MCFT, as described in the following sections.

Assumption in USFM method is to determined concrete principal compression strain $\left(\varepsilon_{2}\right)$, so the result can be obtain from average between two section.[6][7]

$$
\varepsilon_{2}=0.5\left(\varepsilon_{2 i}+\varepsilon_{2 i+1}\right)
$$

The other assumption in USFM is to get the value of strain in column between two sections $\varepsilon_{\mathrm{x}}$.

$$
\varepsilon_{x}=0.5\left(\varepsilon_{x_{i}}+\varepsilon_{x_{i+1}}\right)
$$

Next step is determine concrete principal tensile strain $\varepsilon_{1}$. From modified compression field theory, there are two equilibrium condition

$$
\begin{aligned}
& f_{c x}=f_{c 1}-\tau \cot \theta \\
& f_{c y}=f_{c 1}-\tau \tan \theta
\end{aligned}
$$

Where $f c_{x}$ and $f c_{y}=$ stresses in concrete in the $\mathrm{x}$ (axial) and $\mathrm{y}$ (transverse) directions, respectively; $f c_{l}=$ concrete principal tensile stress; $\tau=$ concrete shear stress; and $\theta$ $=$ crack angle. Using the equilibrium equations above the following relationship can be derived.

$$
\tan ^{2} \theta=\frac{f_{c 1}-f_{c y}}{f_{c 1}-f_{c x}}
$$

The value of crack angle can also be served

$$
\tan ^{2} \theta=\frac{\varepsilon_{x}-\varepsilon_{2}}{\varepsilon_{y}-\varepsilon_{2}}
$$

Where $\varepsilon_{\mathrm{x}}=$ axial strain; $\varepsilon_{\mathrm{y}}=$ strain of transverse reinforcement; and $\varepsilon_{2}=$ concrete principal compression principal tensile strain $\varepsilon_{1}$

$$
\varepsilon_{1}=\varepsilon_{x}+\varepsilon_{y}-\varepsilon_{2}
$$

For the value of $\varepsilon_{\mathrm{y}}, H$. Mostafei [4] assumed that the transversal reinforcement is in yield condition. And the value is 0.002 .

$$
f_{c y}=-\rho_{s y} E_{s} \varepsilon_{y}
$$

Where $\varepsilon_{\mathrm{Y}}=$ strain in the transverse reinforcement $; \mathrm{E}_{\mathrm{s}}=$ modulus of elasticity of the transverse reinforcement.

There are limitation in USFM method so that shear mechanism has no effect on the section analysis.

$$
f_{c 1}=\frac{f^{\prime}{ }_{t}}{1+\sqrt{500 \varepsilon_{1}}} \leq 0.56 f^{\prime}{ }_{t}
$$

The value of $f_{c l}$ between $0.31 f_{t}{ }_{t}$ until $0.56 f_{t}{ }_{t}$.

When cracks occur in element because of shear stress, there is a shear stress limitation using the following Walraven equation:

$$
\tau_{i}=\frac{0.18 \sqrt{f_{c}^{\prime}}}{0.31+\frac{24 w}{a g+16}}(\text { Mpa }, \mathrm{mm})
$$

Where $\mathrm{w}=\mathrm{s}_{\theta} \varepsilon_{1}$ and

$$
S_{\theta}=\frac{1}{\frac{\sin \theta}{S_{x}}+\frac{\cos \theta}{S_{y}}}
$$

where $S x$ and $S y=$ average crack spacing in the $\mathrm{x}$ and $\mathrm{y}$ direction. The requirement on USFM method is

$$
\tau_{\max } \leq \tau_{i}+f_{\text {syy }} \rho_{\text {sy }} \cot \theta
$$

Where $\mathrm{f}_{\text {syy }}=$ transverse reinforcement stress at the crack.

$$
\tau_{\max }=\frac{M}{b h L_{\text {in }}}
$$

Where $\mathrm{M}=$ bottom fixed end moment of the column obtained from the section analysis. 

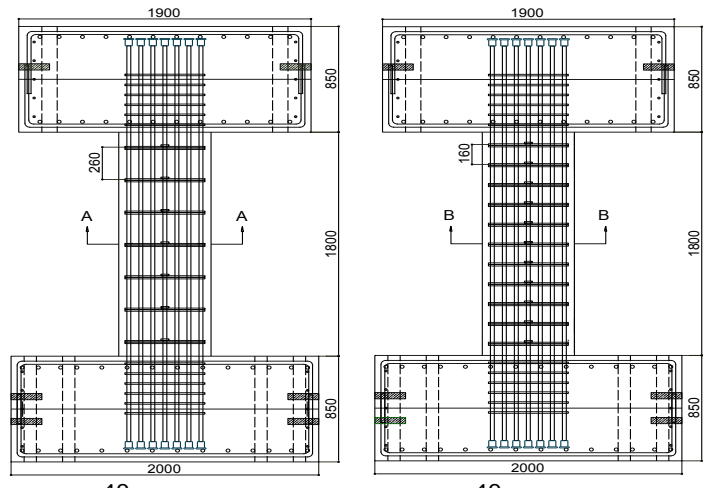

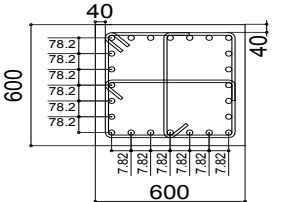

(a)

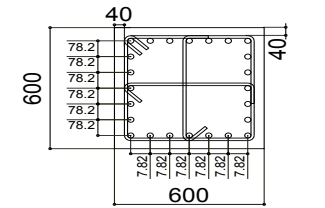

(b)

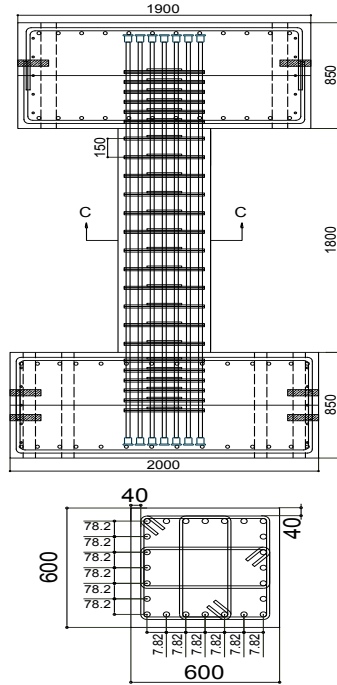

(c)

Figure 7. Specimen Design: (a) specimen A-3.1, B-3.1; (b) specimen B-5, C-5, D-5; (c) specimen A-6, B-6, D-6

When the behavior of high strength reinforcement concrete column calculated, there are differences behavior among research ever done and numerical analysis. Allegedly, there are differences because yield strength of transversal reinforcement is not satisfied if we compared to what we input in numerical analysis. So, we make some modification to solve that problem. We must recalculated the value of yield strength of transversal reinforcement [8].

$$
f_{s}=E_{s}\left(0.0025+0.004 \sqrt[3]{\frac{k_{2} \rho_{c}}{f_{c o}^{\prime}}}\right) \leq f_{y t}
$$

Where $f_{c o}^{\prime}$ is in mega pascals, $k_{2}=$ coefficient that reflects efficiency of confinement reinforcement, $\rho_{c}=$ total transverse steel are in two orthogonal directions divided by corresponding concrete area, $f_{s}=$ tensile stress in transverse reinforcement at peak concrete stress, $f_{y t}=$ yield strength of transverse reinforcement.[7]

$$
k_{2}=0.15 \sqrt{\left(\frac{b_{c}}{s}\right)\left(\frac{b_{c}}{s_{1}}\right)} \leq 1.0
$$

Where $b_{c}=$ core dimensions measured center-to-center of perimeter hoop, $s=$ spacing of transverse reinforcement, $s_{l}=$ spacing of longitudinal reinforcement.

$$
\rho_{c}=\frac{\sum_{i=1}^{n}\left(A_{s x}\right)_{i}+\sum_{j=1}^{n}\left(A_{s y}\right)_{j}}{\left[s\left(b_{c x}+b_{c y}\right)\right]}
$$

Where $\mathrm{n}$ and $\mathrm{m}=$ number of tie legs in $\mathrm{x}-$ and $\mathrm{y}$ directions. Asx, Asy = area of one leg of transverse reinforcement in $\mathrm{x}^{-}$and $\mathrm{y}$-directions, respectively. $b_{c x}, b_{c y}=$ core dimension measured center-to-center of perimeter hoop in $\mathrm{x}$ - and $\mathrm{y}$-directions.

After we know the value of fs, the yield strength of transversal reinforcement can be identified whether satisfied or not. In Figure 6, the value in f'cc is the same with the value of fs, so we can get the new result with modification about yield strength of transversal reinforcement.

$$
\begin{aligned}
& \varepsilon_{01}=0.0028-0.0008 k_{3} \\
& \varepsilon_{085}=\varepsilon_{01}+0.0018 k_{3}{ }^{2} \\
& \varepsilon_{85}=260 k_{3} \rho_{c} \varepsilon_{1}\left[1+0.5 k_{2}\left(k_{4}-1\right)\right]+\varepsilon_{085}
\end{aligned}
$$

where,

$$
\begin{aligned}
& k_{3}=\frac{40}{f^{\prime}{ }_{c o}} \leq 1.0 \\
& k_{4}=\frac{f_{y t}}{500} \geq 1.0 \\
& K=\frac{k_{1} f_{l e}}{f^{\prime}{ }_{c o}} \geq 1.0
\end{aligned}
$$

where,

$$
\begin{aligned}
& k_{1}=6.7\left(f_{l e}\right)^{-0.17} \\
& f_{l e}=k_{2} f_{l} \\
& f_{l}=\frac{\sum_{i=1}^{q}\left(A_{s} f_{s} \sin \alpha\right)_{i}}{s b_{c}}
\end{aligned}
$$

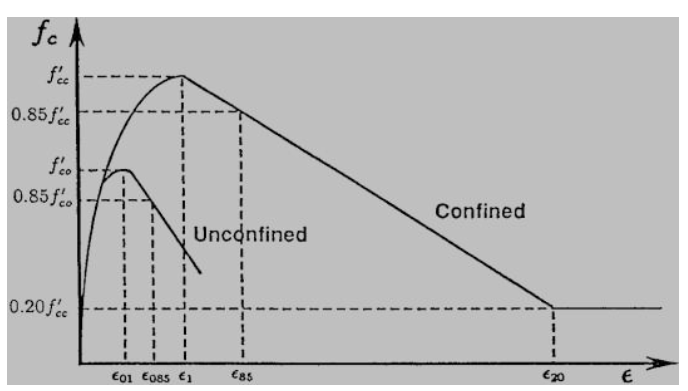

Figure 6. Proposed Model 
The Third International Conference on Civil Engineering Research (ICCER)

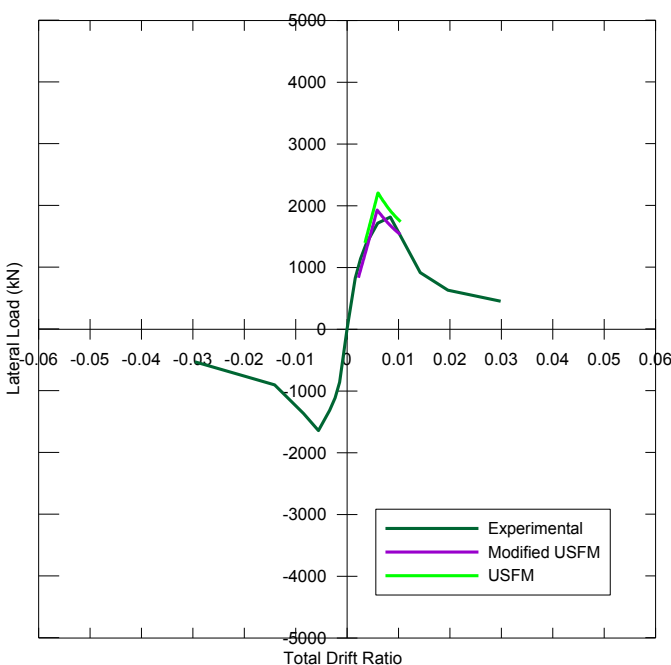

Figure 8. Lateral load vs total drift ratio specimen A3-1

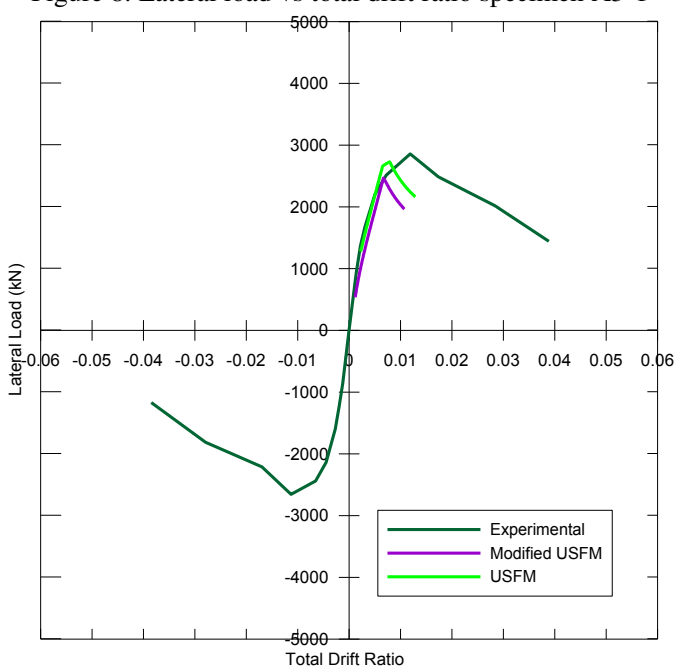

Figure 10. Lateral load vs total drift ratio specimen B3-1

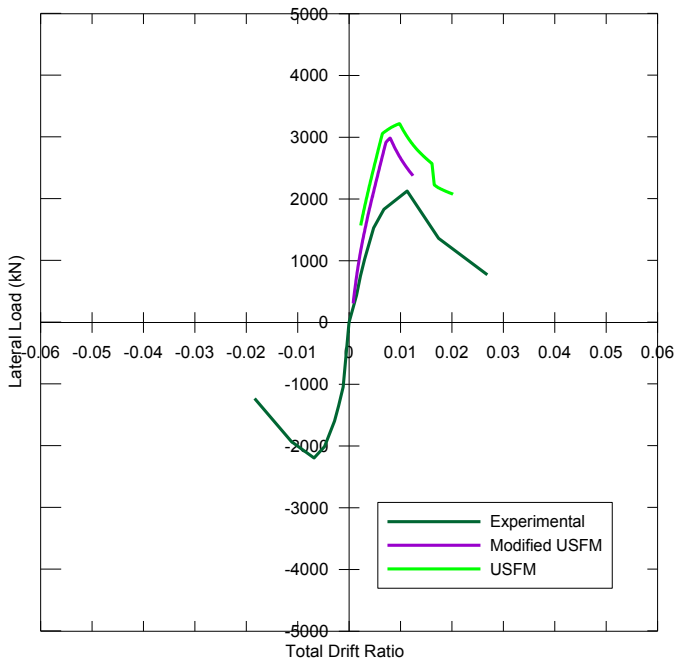

Figure 12. Lateral load vs total drift ratio specimen B6

Where $\varepsilon_{l}=$ strain corresponding to peak stress of confined concrete, $\varepsilon_{01}=$ strain corresponding to peak stress of unconfined concrete, $\varepsilon_{85}=$ strain corresponding to $85 \%$ of peak stress of confined concrete on descending branch, $\varepsilon_{085}=$ strain corresponding to $85 \%$ of peak stress of unconfined concrete on descending branch, $k_{3}=$ coefficient to reflect effect of concrete strength, $k_{4}=$ coefficient to reflect effect of transverse steel strength, fle

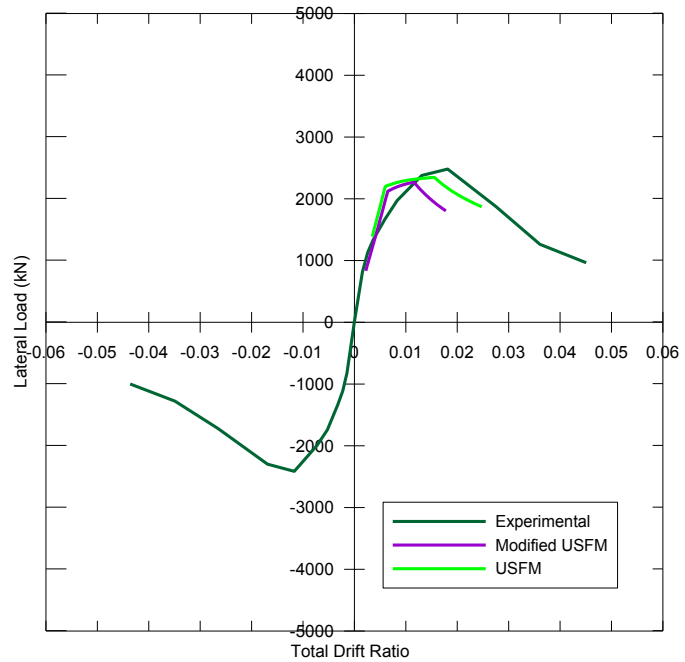

Figure 9. Lateral load vs total drift ratio specimen A6

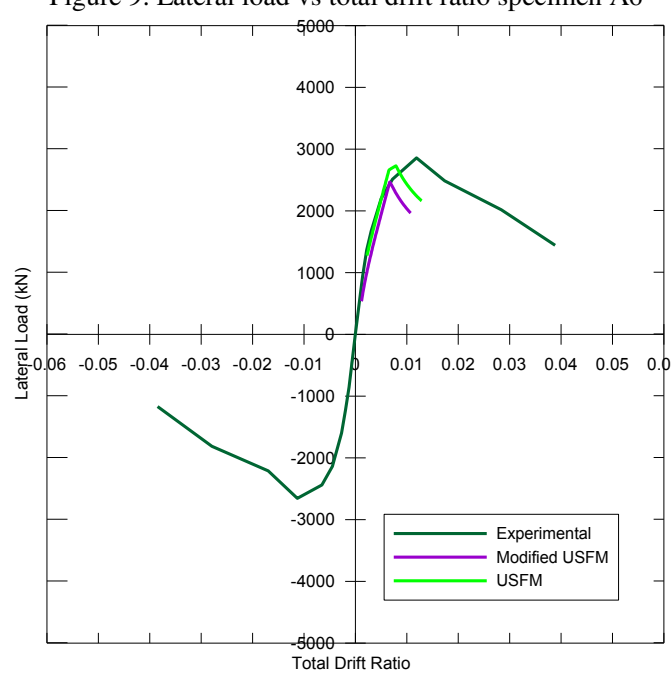

Figure 11. Lateral load vs total drift ratio specimen B5

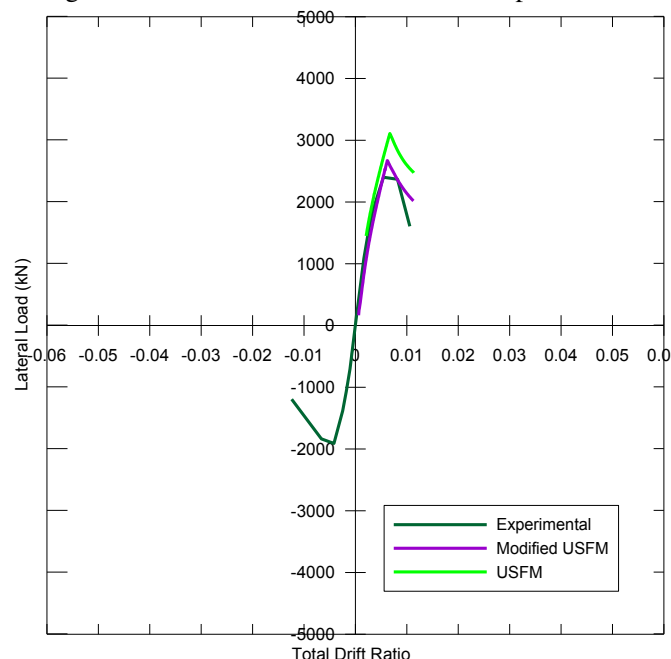

Figure 13. Lateral load vs total drift ratio specimen C5

$=$ equivalent uniform lateral pressure that produces same effect as nonuniform pressure, $f_{l e}=$ average confinement pressure.

Equation 21 until Equation 30 use to draw grap in Figure 6. There are two condition in the graph, first is ascending branch and the second is descending branch. For ascending branch there are equation to get specified stress in concrete. 
August $1^{\text {st }}-2^{\text {nd }}$ 2017, Surabaya - Indonesia

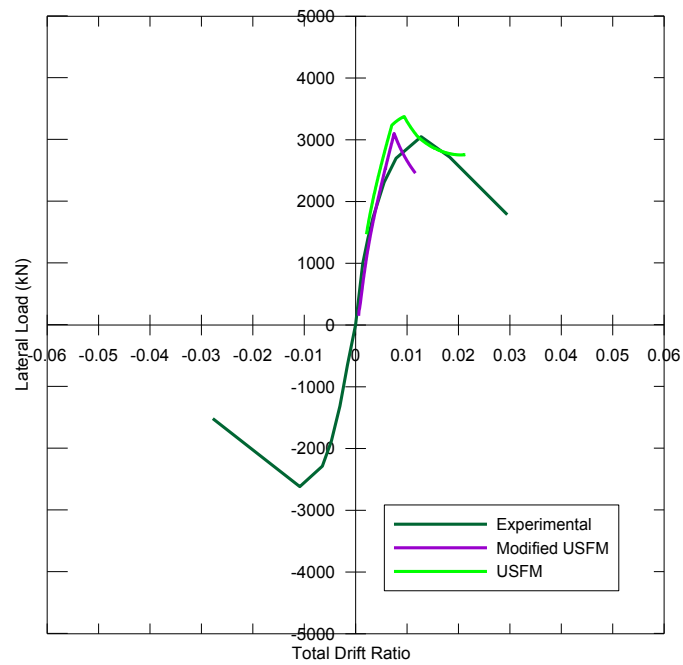

Figure 14. Lateral load vs total drift ratio specimen C6

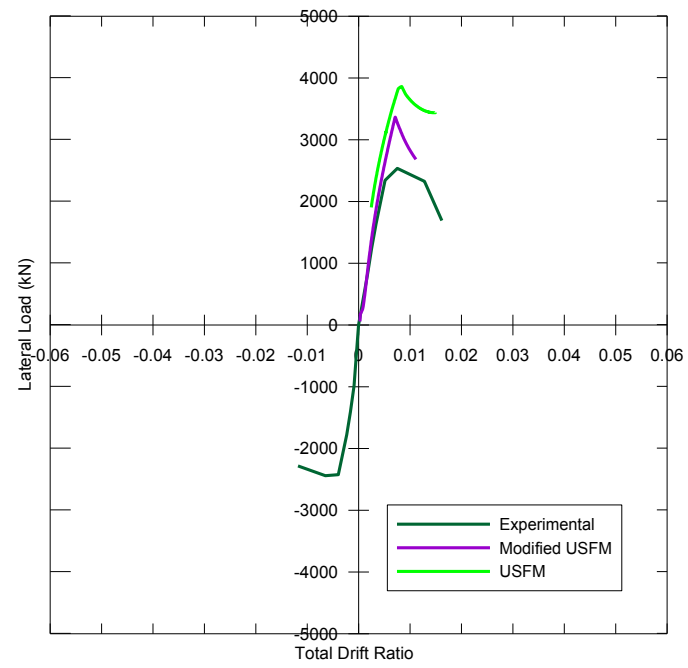

Figure16. Lateral load vs total drift ratio specimen D6

$$
f_{c}=\frac{f^{\prime}{ }_{c c}\left(\frac{\varepsilon_{c}}{\varepsilon_{1}}\right) r}{r-1+\left(\frac{\varepsilon_{c}}{\varepsilon_{1}}\right)^{r}}
$$

$$
r=\frac{E_{c}}{E_{c}-E_{\mathrm{sec}}}
$$

Where $\mathrm{E} \mathrm{sec}=$ secant modulus of elasticity of confined concrete and can be calculated from Equation 33

$$
E_{\mathrm{sec}}=\frac{f_{c c}}{\varepsilon_{1}}
$$

Where $\mathrm{E} \mathrm{c}=$ modulus elasticity of unconfined concrete. The following expression, originally proposed by Carrasquillo et al. [8] is found to produce food agreement with experimentally obtained values

$$
E_{c}=3320 \sqrt{f^{\prime}{ }_{c}}+6900
$$

Where f'c is in mega pascals. $E_{c}$ should be greater than $E_{\text {sec. }}$.

For Descending branch there are equation to get

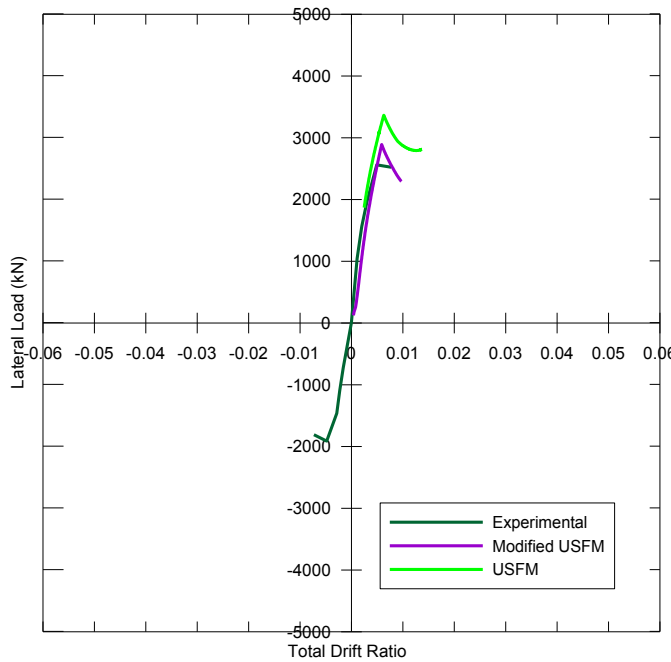

Figure 15. Lateral load vs total drift ratio specimen D5

Table 2.

The Result of Lateral Load

\begin{tabular}{ccccccc}
\hline & $f^{\prime}{ }_{c}$ & $\rho_{w}$ & & \multicolumn{3}{c}{ Lateral Load $(\mathrm{kN})$} \\
\cline { 5 - 7 } Column & $(\mathrm{Mpa})$ & $(\%)$ & $P / A_{g} f^{\prime}{ }_{c}$ & USFM & $\begin{array}{c}\text { Modified } \\
\text { USFM }\end{array}$ & Experimental \\
\hline A-3.1 & 92.2 & 0.26 & 0.1 & 2206.68 & 2083.23 & 1817.11 \\
A-6 & 90.8 & 0.59 & & 2345.01 & 2321.47 & 1998.60 \\
B-3.1 & 78 & 0.26 & 0.2 & 2306.32 & 2187.28 & 1998.60 \\
B-5 & 78 & 0.41 & & 2728.07 & 2663.73 & 2856.45 \\
B-6 & 101.1 & 0.59 & & 3218.66 & 3147.06 & 2128.91 \\
C-5 & 79.6 & 0.41 & 0.3 & 3108.56 & 3020.64 & 2399.98 \\
C-6 & 80.3 & 0.59 & & 3375.41 & 3345.34 & 3048.26 \\
D-5 & 82.8 & 0.41 & 0.4 & 3363.38 & 3258.69 & 2560.34 \\
D-6 & 84.9 & 0.59 & & 3861.53 & 3827.33 & 2535.34 \\
\hline
\end{tabular}

specified stress in concrete.

$$
f_{c}=\frac{\left(\varepsilon_{c}-\varepsilon_{85}\right)}{\left(\varepsilon_{1}-\varepsilon_{85}\right)} 0.15 f^{\prime}{ }_{c c}+0.85 f^{\prime}{ }_{c c}
$$

So with new specified stress that occur in specified strain, Hopefully the result between experimental and numerical analysis is similar.

In this paper will be calculated 9 specimens of high strength reinforced concrete column with numerical analysis shown in Table 1. There are several parameters in that Table. The parameters are Type of the column, ratio of axial load, strngth concrete, yield strength of longitudinal reinfocement, yield strength of transversal reinforcement and size of bar reinforcement. In that table 1 , there are four types of ratio of axial load, that is 0.1 $P / A_{g} f_{c}{ }_{c}, 0.2 P / A_{g} f_{c}{ }_{c}, 0.3 P / A_{g} f_{c}{ }_{c}, 0.4 P / A_{g} f_{c}{ }_{c}$. In Figure 7 there are three types for sepcimen design and the differences at three types og specimen design is spacing and amount of leg of transversal reinforcement. Figure $7 \mathrm{a}$ is for A-3.1, B-3.1, Figure $7 \mathrm{~b}$ is for B-5, C-5, D-5 and Figure 7c is for A-6, B-6, C-6, D-6. The result from experimental will be coMPared with numerical analysis using USFM method and modified USFM method. 


\section{RESULTS AND DISCUSSION}

The behavior shear strength of high strength reinforced concrete column between numerical analysis and experimental is similar. In Figure 8 shown that specimen column A3-1 relationship between Lateral Load $(\mathrm{kN})$ and Total Drift Ratio is quite similar with experimental. The yield strength of transversal reinforcement bar in modified USFM method is not satisfied. In Figure 9 shown that specimen column A6 is quite similar too and yield strength of transversal reinforcement is not satisfied. Behavior in modified USFM and USFM is similar to experimental. Figure 10 shown that specimen column B3-

1 is similar with modified USFM method, it because the transversal reinforcement is not yield. In figure 11 shown specimen B5. The lateral load in experimental is higher than numerical analysis. Allegedly, it because in the numerical analysis the transversal reinforcement is not yield, but in the experimental it can be not yield.

Figure 12-16 shown specimen design for B6, C5, C6, D5, D6. There are behavior differences between the result of numerical analysis and the result of experimental. This is may cause by the specimen tend to fail in flexure condition rather than shear condition.

In Table 2 shown that the result of Lateral Load between Experimental, USFM and modified USFM. Lateral Load in Modified USFM is more similar with experimental than USFM.

\section{CONCLUSION}

After analyze the results of this research, it can be concluded that:

1. The modification of calculation stress of transverse reinforcement at improve shear prediction particularly for columns with low axial compression

2. The behavior in modified USFM has similar result with the result of experimental, this method is improved USFM and provide better prediction.

\section{REFERENCES}

[1] H. Aoyama, Design of Modern Highrise Reinforced Concrete Structures. London: Imperial College Press, 2001.

[2] M. A. Caldarone, High-Strength Concrete - A Practical Guide. New York: Taylor \& Francis Ltd., 2008.

[3] H. Alrasyid, "Seismic Shear Behavior of High-Strength Reinforced Concrete Columns," National Taiwan University of Science and Technology, 2016.

[4] H. Mostafaei, "Uniaxial Shear-Flexure Model for Reinforced Concrete Elements," J. Eng. Struct., 2008.

[5] H. Mostafaei and Kabeyasawa, "Axial-Shear-Flexure Interaction Approoach for Reinforced Concrete Columns," ACI Struct. J., 2007.

[6] Y.-C. Ou and Kurniawan, "Shear Behavior of Reinforced Concrete Columns With High-Strength Steel and Concrete," ACI Struct. J., vol. 112, no. 1, pp. 35-45, 2015.

[7] F. Watanabe and T. Kabeyasawa, "Shear Strength of RC Members with High-Strength Concrete," in Proc., SP-176: High-Strength Concrete in Seismic Regions, 1991.

[8] S. Razvi and M. Saatcioglu., "Confinement Model for HighStrength Concrete," J. Struct. Enggineering, 1999. 